\title{
Diversity of Weissella confusa in Pozol and Its Carbohydrate Metabolism
}

\author{
Diana Hernández-Oaxaca1, Rafael López-Sánchez¹, Luis Lozano², \\ Carmen Wacher-Rodarte ${ }^{3}$, Lorenzo Segovia' and Agustín López Munguía ${ }^{1 *}$
}

${ }^{1}$ Departamento de Ingeniería Celular y Biocatálisis, Instituto de Biotecnología, Universidad Nacional Autónoma de México (UNAM), Cuernavaca, Mexico, ${ }^{2}$ Programa de Genómica Evolutiva, Centro de Ciencias Genómicas, Universidad Nacional Autónoma de México (UNAM), Cuernavaca, Mexico, ${ }^{3}$ Departamento de Alimentos y Biotecnología, Facultad de Química, Universidad Nacional Autónoma de México (UNAM), Ciudad de México, Mexico

\section{OPEN ACCESS}

Edited by:

Vincenzina Fusco,

Institute of Sciences of Food

Production, Italian National Research

Council, Italy

Reviewed by:

Yasuhiro Tanizawa,

National Institute of Genetics (Japan),

Japan

Folarin Anthony Oguntoyinbo, Appalachian State University, United States

*Correspondence:

Agustín López Munguía agustin.lopez@ibt.unam.mx

Specialty section:

This article was submitted to

Food Microbiology,

a section of the journal

Frontiers in Microbiology

Received: 14 November 2020

Accepted: 24 February 2021

Published: 18 March 2021

Citation:

Hernández-Oaxaca $D$, López-Sánchez R, Lozano L, Wacher-Rodarte C, Segovia $L$ and López Munguía A (2021) Diversity of Weissella confusa in Pozol and lts

Carbohydrate Metabolism.

Front. Microbiol. 12:629449.

doi: 10.3389/fmicb.2021.629449
The genus Weissella is composed of a group of Gram-positive facultative anaerobe bacteria with fermentative metabolism. Strains of this genus have been isolated from various ecological niches, including a wide variety of fermented cereal foods. The present study aimed to determine the relative abundance and fermentation capabilities of Weissella species isolated from pozol, a traditional maya product made of limecooked (nixtamalized) fermented maize. We sequenced the $\mathrm{V} 3-\mathrm{V} 4$ regions of $16 \mathrm{~S}$ rDNA; Weissella was detected early in the fermentation process and reached its highest relative abundance (3.89\%) after $3 \mathrm{~h}$ of culture. In addition, we evaluated five Weissella strains previously isolated from pozol but reported as non-amylolytic, to define alternative carbon sources such as xylan, xylooligosaccharides, and sucrose. While no growth was observed on birch xylan, growth did occur on xylooligosaccharides and sucrose. Strains WCL17 and WCP-3A were selected for genomic sequencing, as the former shows efficient growth on xylooligosaccharides and the latter displays high glycosyltransferase (GTF) activity. Genomes of both strains were assembled and recorded, with a total of $2.3 \mathrm{Mb}$ in 30 contigs for WcL17 and $2.2 \mathrm{Mb}$ in 45 contigs for WCP-3a. Both strains were taxonomically assigned to Weissella confusa and genomic analyses were performed to evaluate the gene products encoding active carbohydrate enzymes (CAZy). Both strains have the gene content needed to metabolize sucrose, hemicellulose, cellulose, and starch residues, all available in pozol. Our results suggest that the range of secondary enzymatic activity in Weissella confusa strains confer them with wide capabilities to participate in fermentative processes of natural products with heterogeneous carbon sources.

Keywords: pozol, maize, Weissella, fermented foods, CAZy

\section{INTRODUCTION}

Pozol, from the Nahuatl pozolli, is an acidic beverage obtained from the non-alcoholic fermentation of nixtamalized (lime-cooked) maize. In ancient times, it was one of the most important cultural components used by peninsular Mayans in offerings to the gods and spirits in ceremonies related to maize cultivation and harvest (Vassallo Rodríguez, 2016). It is currently consumed in 
southeastern Mexico, where it remains as a food of nutritional, cultural, and economic importance (Sangwan et al., 2014).

The microbial complexity involved in pozol fermentation has been studied for several decades using microbiological, biochemical, and molecular techniques, as there is no established inoculation procedure. A number of facts are currently known in this regard. On the one hand, lactic acid bacteria (LAB) are dominant in all stages of pozol fermentation (Wacher et al., 1993; Nuraida et al., 1995; ben Omar and Ampe, 2000). On the other, the microbiota involved in pozol fermentation is complex, including filamentous fungi and yeasts observed in outer layers, while bacteria are found mainly at the core of the dough ball (Ampe et al., 1999a). Multiple bacterial genera have been identified in pozol, with Streptococcus and Weissella being frequently mentioned in the scientific literature on pozol (Ampe et al., 1999b; ben Omar and Ampe, 2000; Wacher et al., 2000; Escalante et al., 2001; Bolaños et al., 2006; Cárdenas et al., 2014). Strains isolated from pozol synthesize broadspectrum antimicrobial compounds that can be used as food preservatives (Ray et al., 2000; Phister et al., 2004). Moreover, exopolysaccharides synthesized from sucrose may function as soluble fiber or prebiotics (Olivares-Illana et al., 2002).

As regards the source of carbon, starch is the main carbohydrate available in nixtamalized maize. In this sense, amylolytic lactic-acid bacteria (ALAB) in the genera Enterococcus, Lactococcus and Streptococcus have been identified in pozol, with S. bovis (Streptococcus infantarius ssp. infantarius) as the species with the highest specific growth rate on starch, but with low amylase activity relative to other ALAB species (Díaz-Ruiz et al., 2003). No amylase activity was found in Weissella strains (López-Hernández et al., 2018), as also reported for Weissella strains in other cereal-based fermented foods (Sharma et al., 2018).

It has been suggested that the hemicellulose available after nixtamalization may be an alternative substrate for dough fermentation. In this context, it was recently demonstrated that S. infantarius isolated from pozol can assimilate xylan in nejayote (residual water from nixtamalization) and xylan from birch wood through xylanolytic activity (Cooper-Bribiesca et al., 2018). Similarly, W. confusa L9 strain assimilates xylooligosaccharides (XOS) in nixtamalized corn (López-Hernández et al., 2018). Activities of this sort have been identified in sourdough fermentation, for which the destructuring of insoluble fiber and an increase in soluble dietary fiber after fermentation have been reported (Decimo et al., 2017). Furthermore, the consumption of XOS by strains of this genus isolated from Indian fermented foods has also been described (Patel et al., 2013).

Interestingly, Weissella strains have been isolated from highly diverse fermented products (Fusco et al., 2015), including jeotgal and kimchi, nono and douchi, among many others (Lee et al., 2010; Ayeni et al., 2011; Liu et al., 2012). Moreover, the presence of $W$. confusa in multiple types of fermented food with cereal as fermentation matrix is a remarkable finding (Ampe et al., 1999b; Mugula et al., 2003; Abegaz, 2007; Bounaix et al., 2010; Oguntoyinbo et al., 2011; Owusu-Kwarteng et al., 2012; Elizaquível et al., 2015; Osimani et al., 2015; Kavitake et al., 2016). Furthermore, several Weissella strains isolated from fermented foods produce exopolysaccharides from sucrose, particularly dextran (Tieking et al., 2003; Park et al., 2013; Malang et al., 2015; Shukla et al., 2016; Rizzello et al., 2019). Dextran has also been detected in products made from wheat and rye bran fermented by two Weissella confusa strains isolated from fermented vegetables (Kajala et al., 2016), and in quinoa-flour yogurt added with sucrose (Lorusso et al., 2018). This ability to synthesize exopolysaccharides with soluble-fiber or prebiotic potential through glycosyltransferase (GTF) activity is an additional interesting feature of this genus (Malang et al., 2015).

Based on this background, we evaluated the importance of the genus Weissella in terms of its presence throughout the pozol fermentation process. In addition, we explored the biochemical and genomic ability of Weissella strains isolated from pozol to assimilate birch xylan, XOS, and sucrose as alternative carbon sources in pozol fermentation, as well as the presence of GTF activity.

\section{MATERIALS AND METHODS}

\section{Mass Sequencing of the 16S rDNA Marker in Pozol Samples}

Pozol samples were prepared as described in Rizo et al. (2020). Freshly ground nixtamal dough samples were obtained from two producers at the Pino Suárez market in Tabasco, Mexico. Triplicate samples were mixed and shaped into 300-g balls, wrapped in banana leaves, and incubated at $37^{\circ} \mathrm{C}$. Sampling was performed at $0,9,24$, and $48 \mathrm{~h}$, and handled aseptically. DNA was extracted with commercial kits (PowerSoil DNA Isolation Kit, PowerMax Soil DNA Isolation Kit, and UltraClean Microbial DNA Isolation Kit (MO BIO, QIAGEN). DNA was purified and, using specific oligonucleotides (Klindworth et al., 2013), the V3-V4 region of the $16 \mathrm{~S}$ rDNA marker was amplified with Phusion High-Fidelity DNA Polymerase (Thermo Scientific). Amplicons were sequenced on an Illumina MiSeq $(2 \times 300 \mathrm{bp})$ platform. Amplicons were reconstructed with Flash v1.2.7 (Magoč and Salzberg, 2011). All non-overlapping sequences were excluded from further analyses. The extended fragments were dereplicated, chimeras were removed, and singletons were filtered with VSEARCH-v2.4.3 (Rognes et al., 2016), generating an OTUs matrix of $97 \%$ similarity. The taxonomic annotation was conducted with the ParallelMeta v2.4.1 software (Su et al., 2014) and the Metaxa2 v2.1.1 software (Bengtsson-Palme et al., 2015), as described in Escobar-Zepeda et al. (2018). Rarefaction curves and alpha diversity indexes were prepared with the $\mathrm{R}$ libraries metagenomeSeq (Paulson et al., 2013) and phyloseq (McMurdie and Holmes, 2013). An NDMS plot was constructed using the dissimilitude Bray-Curtis index with the vegan package in R (Oksanen et al., 2012).

\section{Microorganisms and Culture Conditions}

Five Weissella strains (WcSnc45, WcSnc40, WcL9, WcL17, and WCP-3a) isolated from pozol were included in this study LópezHernández et al. (2018). These strains were preserved in glycerol at $-80^{\circ} \mathrm{C}$. A $10 \%(\mathrm{v} / \mathrm{v})$ aliquot was inoculated to De Man Rogosa and Sharpe (MRS) medium (Diffco, United States), 
which was incubated at $30^{\circ} \mathrm{C}$ for $24 \mathrm{~h}$. Afterward, a $10 \%(\mathrm{v} / \mathrm{v})$ aliquot was transferred to MRS broth and incubated at $30^{\circ} \mathrm{C}$ for $12 \mathrm{~h}$; the latter was used as inoculum for fermentation experiments. Additionally, a $0.6 \%(\mathrm{v} / \mathrm{v})$ aliquot was inoculated in $1 \%$ modified glucose-free MRS broth, prepared by adding three carbon sources: birch xylan, xylooligosaccharides (XOS), and sucrose, as proposed by López-Hernández et al. (2018). The media were incubated at $30^{\circ} \mathrm{C}$ for $48 \mathrm{~h}$; samples were collected at different times over the culture period to observe the evolution of $\mathrm{pH}$ and measure optical density (OD) at $600 \mathrm{~nm}$, used to calculate the growth rate. The culture supernatant was recovered by centrifugation at $16000 \mathrm{~g}$ for $10 \mathrm{~min}$ and then transferred to two Eppendorf tubes, one of which was inactivated by heating in boiling water for $10 \mathrm{~min}$; both tubes were stored at $-4^{\circ} \mathrm{C}$.

\section{Growth Kinetics in Birch Xylan, Xylooligosaccharides, and Sucrose}

Growth of the five strains in MRS-birch xylan, MRS-XOS, and MRS-sucrose was followed for $48 \mathrm{~h}$, with the non-inactivated enzymatic extract used to measure enzymatic activity. Biological and experimental replicates were run in duplicate in all tests and analyzed using the ggpubr package in R v4.0.2. Significant differences were examined with a Tukey post hoc test after a Kruskal-Wallis test. The detailed procedure is described in the repository, Data Availability section. Xylanolytic and GTF activities were determined through the quantification of reducing sugars using the dinitrosalicylic acid (DNS) method (Miller, 1959). A standard xylose curve (Sigma, United States) (0-2 g/L) was used as reference for xylanolytic activity calculations. The reaction mixture contained $300 \mu \mathrm{L}$ of substrate $(0.5 \%$ birch xylan in $0.1 \mathrm{M}$ acetate buffer, $\mathrm{pH} 5.3$ ) and $300 \mu \mathrm{L}$ of culture supernatant. The reaction was incubated at $50^{\circ} \mathrm{C}$ and $800 \mathrm{rpm}$ for $6 \mathrm{~h}$, collecting $50 \mu \mathrm{L}$ reaction samples at 0,3 , and $6 \mathrm{~h}$. A standard curve of glucose and fructose (Sigma, United States) (0-2 g/L) was used as reference for GTF activity measurements. The reaction mixture contained $50 \mu \mathrm{L}$ of $60 \%$ sucrose, $150 \mu \mathrm{L}$ of $50 \mathrm{mM}$ acetate buffer, $\mathrm{pH} 6.0$, and $300 \mu \mathrm{L}$ of supernatant. The reaction was incubated at $37^{\circ} \mathrm{C}$ and stopped at $0,10,20$, and $30 \mathrm{~min}$. In both cases, the enzyme was inactivated by adding $50 \mu \mathrm{L}$ of DNS and then used to measure the reducing sugars. The sample was incubated at boiling temperature for $5 \mathrm{~min}$ and transferred to ice for $5 \mathrm{~min}$. Five-hundred milliliters of distilled water were added, and absorbance was read at $540 \mathrm{~nm}$ using the $0 \mathrm{~h}$ time point as blank.

As regards the kinetics with MRS-sucrose, the strains that showed the greatest growth were re-evaluated. The inactivated supernatants were used to determine the amount of sucrose metabolized throughout the fermentation process by highperformance liquid chromatography (HPLC) and polymer formation by gel permeation chromatography (GPC), as reported by Porras-Domínguez et al. (2015). Xyloligosaccharides were produced from birch xylan following the procedure of Akpinar et al. (2009) and later used as substrate to measure xylosidase activity and for kinetics studies in MRS-XOS Weissella cultures. Based on these results, the strain showing the highest growth (WcL17) was selected for further studies. Samples of the inactive culture extract were used to evaluate the metabolized XOS profile by thin-layer chromatography (TLC) in silica gel-coated aluminum plates (Merck, Germany). To this end, $20 \mu \mathrm{g}$ of sample was run twice with a mobile phase of 15:9:6 (v/v/v) ethanol:butanol:water; plates were air-dried and revealed with $\propto$-naphthol and heat. At the same time, XOS metabolized during fermentation were evaluated using ionexchange chromatography (HPAEC)-PAD (18). For enzymatic activity, $180 \mu \mathrm{L}$ of non-inactivated supernatant was incubated with $180 \mu \mathrm{L}$ of XOS and $40 \mu \mathrm{L}$ of $0.1 \mathrm{M}$ acetate buffer, $\mathrm{pH}$ 6.0. The reaction was incubated at $37^{\circ} \mathrm{C}$ and $800 \mathrm{rpm}$ for $5 \mathrm{~h}$. The XOS hydrolysis and xylose accumulation were confirmed by TLC and HPAEC-PAD. Standards of xylose (X1), xylobiose (X2), xylotriose (X3), xylotetraose (X4), xylopentose (X5), and xylohexose (X6) (Megazyme, Ireland) were used in all assays.

\section{Genome Sequencing, Assembly, and Annotation}

Strains WCP-3a and WcL17 were selected for genome sequencing based on their GTF and $\beta$-xylosidase activities, respectively. DNA was extracted with the commercial UltraClean Microbial DNA Isolation Kit (MO BIO, QIAGEN) following the manufacturer's specifications. The extracted DNA was sequenced in the Mass Sequencing Unit of the Institute of Biotechnology at Universidad Nacional Autónoma de México, in an Illumina NextSeq500 platform $(2 \times 75$ bp $)$ and a 550 bp insert. Adapters were eliminated with the program Trim Galore v0.4.4 (Krueger, 2015) and de novo assemblies were generated with Velvet v.2.2.5 (Zerbino and Birney, 2008) and SPAdes v3.11.1 (Bankevich et al., 2012); these were subsequently merged with Metassembler v1.5 (Wences and Schatz, 2015). Contigs underwent a scaffolding process with SSPACE v3.0 (Boetzer et al., 2011) and were refined with GapFiller v1.10 (Boetzer and Pirovano, 2012). Gene prediction and annotation were performed with Prokka v1.12 (Seemann, 2014).

\section{Taxonomic Assignment of Sequenced Genomes}

Fifty-five ribosomal proteins were selected using local scripts from the sequenced genomes, as well as from representative genomes of each species of Weissella available in databases at the time of analysis (November 2017) (Table 1). Additionally, the housekeeping genes encoding D-Ala-D-Ala ligase (dll), phosphoglucomutase ( $\mathrm{pgm}$ ), glucose 6-phosphate dehydrogenase $(g 6 p d)$, RNA polymerase subunit beta $(r p o B)$, RNA polymerase subunit alpha $(r p o A)$, and phenylalanine tRNA synthetase subunit alpha ( $p h e S$ ) were selected to construct the second phylogeny. Sequences were aligned with MUSCLE v3.8.1551 (Edgar, 2004); the prediction of the phylogenetic model was carried out with ProtTest3 (Darriba et al., 2011), and the construction of the maximum likelihood phylogeny with RaxML v8.2.10 (Stamatakis, 2014) using 100 bootstrap replicates. In addition, an average nucleotide identity (ANIm) analysis was performed with pyani v0.2.9 (Pritchard et al., 2016) using genomes representative of the genus Weissella and those assembled in this paper (Table $\mathbf{1}$ ). 
TABLE 1 | Overall properties of representative Weissella genomes sequenced in this work, including W. confusa strains WcL17 and WCP3a.

\begin{tabular}{|c|c|c|c|c|c|c|}
\hline Species & Size (Mb) & Contigs & N50 & Source & Origin & References (Refseq) \\
\hline W. bombi R-53094 & 1.82 & 30 & 114246 & N/D & N/D & GCF_900094835.1 \\
\hline W. cibaria $\mathrm{CH} 2$ & 2.57 & 1 & - & Fermented foods & India & GCF_001308145.2 \\
\hline W. confusa LBAE C39-2 & 2.28 & 71 & 63653 & Wheet sourdough & France & GCF_000239955.1 \\
\hline W. confusa DSM 20196 & 2.21 & 82 & 96695 & Cured sausages & China & GCF_001436895.1 \\
\hline W. confusa MBF8-1 & 2.18 & 44 & 84171 & Fermented soya & Indonesia & GCF_001884305.1 \\
\hline W. confusa AB3E41 & 2.25 & 54 & 146189 & African beer broth & Ivory coast & GCF_900166935.1 \\
\hline W. confusa WcL17 & 2.31 & 30 & 155975 & Pozol & Mex, Tab. & GCA_015594935.1 \\
\hline W. confusa WCP3a & 2.22 & 45 & 119794 & Pozol & Mex, Chis. & GCA_015594955.1 \\
\hline W. halotolerans DSM & 1.35 & 8 & 325056 & Sausages & Germany & GCF_000420365.1 \\
\hline W. hellenica R-53116 & 1.81 & 33 & 99337 & $\mathrm{~N} / \mathrm{D}$ & $\mathrm{N} / \mathrm{D}$ & GCF_900095015.1 \\
\hline W. jogaejeotggali FOL01 & 2.14 & 1 & - & Korean seafood & South Korea & GCF_001932615.1 \\
\hline W. Kandleri DSM 20593 & 1.33 & 36 & 96380 & Fermented sausages & China & GCF_001438705.1 \\
\hline W. koreensis KACC 15510 & 1.44 & 1 & - & Kimchi & South Korea & GCF_000219805.1 \\
\hline W. minor DSM 20014 & 1.76 & 50 & 123342 & Fermented sausages & China & GCF_001437425.1 \\
\hline W. oryzae SG25 & 2.12 & 72 & 148611 & Fermented rice & Japan & GCF_000691805.2 \\
\hline W. paramesenteroides ATCC 33313 & 1.98 & 36 & 106888 & Humans & $\mathrm{N} / \mathrm{D}$ & GCF_000160575.1 \\
\hline W. viridescens DSM 20410 & 1.53 & 34 & 86165 & N/D & N/D & GCF_001437355.1 \\
\hline
\end{tabular}

\section{Comparative Genomic of Active Carbohydrate Enzymes Through the Genus Weissella}

We performed a comparative analysis of the genomes sequenced in this paper and those representative of the genus Weissella (Table 1) for which the genomes discharged were re-annotated with Prokka v1.12 (Seemann, 2014). The amino acid sequences obtained were mapped with HMMER v3.1b2 hmmscan (Eddy, 2011) against the database of preserved domains of all Carbohydrate Enzymes (CAZy) families following the protocol proposed by dbCAN (Yin et al., 2012).

\section{RESULTS}

\section{Structure of the Bacterial Community of Pozol Over Fermentation Time}

The structure and succession of bacterial communities in pozol were analyzed by amplicon sequencing at $0,9,24$, and $48 \mathrm{~h}$ of culture. These time points represent the beginning of the fermentation process, the peak microbial growth, the shift in the microbial community and the end of that shift, respectively. From those time points, a total of 31,199 bacterial operational taxonomic units (OTUs) were obtained from all samples, distributed in 1,042 bacterial genera. As shown in Supplementary Table 1, the highest diversity in the bacterial community was found after $9 \mathrm{~h}$ of fermentation, and the lowest at $0 \mathrm{~h}$. These results are similar to those reported in the literature on pozol (Ampe et al., 1999b; Ampe and Miambi, 2000; Wacher et al., 2000; Escalante et al., 2001; Bolaños et al., 2006; Cárdenas et al., 2014). According to the results on $\beta$-diversity, the $9 \mathrm{~h}$ and 24 -h samples are similar in microbial composition (Shannon-Weaver index of 5.25 and 5.27, respectively), while the 0 -h and 48 -h samples are different from the rest (Shannon-Weaver index of 2.72 and
4.95) (Supplementary Table 1). The sampling procedure was successful in describing the community structure, except for the sample at $48 \mathrm{~h}$ (Supplementary Figure 2).

As regards relative abundance, the main bacteria involved in pozol fermentation are lactic-acid bacteria from the phylum Firmicutes. At $0 \mathrm{~h}$, the genera Anoxybacillus, Exiguobacterium, and Bacillus make more than $50 \%$ of the genera found (33.42, 22.92 , and $19.11 \%$, respectively), while Weissella accounted for $0.05 \%$. On the other hand, the least represented genus was Acetobacter, with $0.00069 \%$. After $9 \mathrm{~h}$ of fermentation, Streptococcus was the most abundant genus, with $44.19 \%$, while Weissella ranked eighth among the 25 genera identified, with $3.89 \%$. At $24 \mathrm{~h}$ of fermentation, Streptococcus remained as the most abundant genus, with $41.02 \%$, while Weissella ranked 12 th, with $1.89 \%$. For the sample collected at the end of the process, after $48 \mathrm{~h}$ of fermentation, Streptococcus remained as the most abundant genus, with $38.94 \%$, and Weissella ranked eleventh, with $1.80 \%$ (Figure 1). It is worth mentioning that Lactobacillus increased in relative abundance from an initial 0.07 to $15 \%$ after $48 \mathrm{~h}$ of pozol fermentation.

\section{Growth Kinetics and Enzymatic Activity on Birch Xylan}

There was little growth of the strains studied when birch xylan was used as carbon source; the assessment of $\mathrm{pH}$ revealed no changes throughout the sampling period, remaining constant at 6.5 in all samples. Accordingly, xylanolytic activity was null at all sampling points (Supplementary Figure 3).

\section{Growth Kinetics and Xylooligosaccharide Metabolism Profile}

Given the poor growth observed in birch xylan and based on the fact that the Weissella strains analyzed possess no amylolytic activity but can metabolize xylose (López-Hernández et al., 2018), we decided to assess their ability 


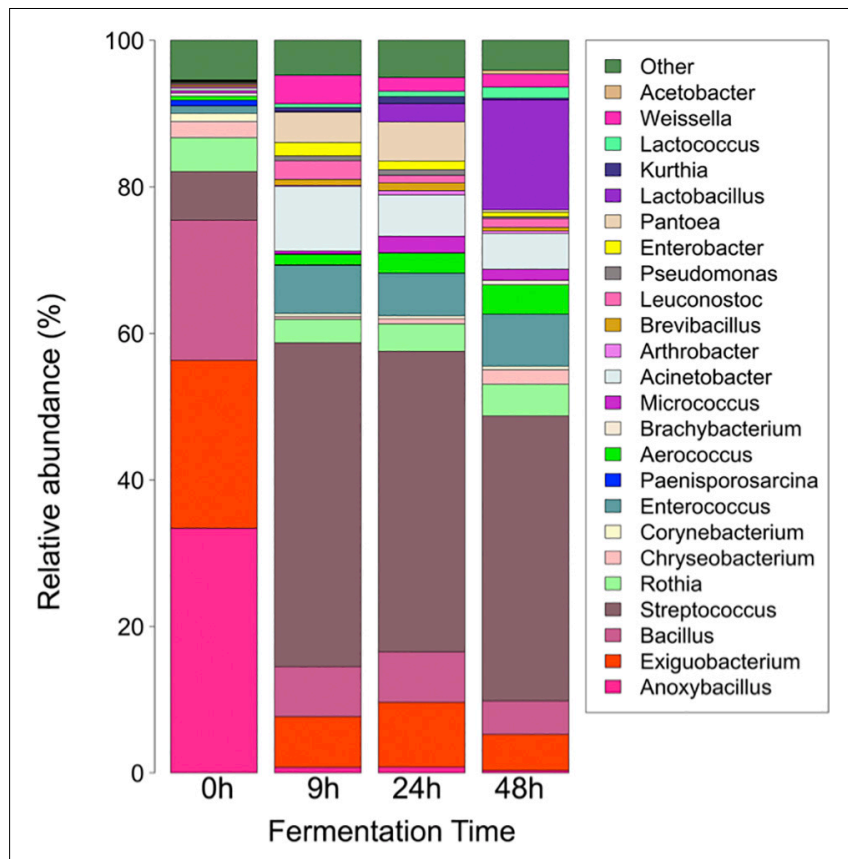

FIGURE 1 | Change in the structure of pozol bacterial communities over fermentation time. Taxonomic assignation was made by metabarcoding (V3-V4, 16S r DNA). "Other" includes all genera with relative abundance lower than $0.05 \%$.

to metabolize XOS. As shown in Figure 2, all strains have the ability to metabolize XOS; the strain WcL17 showed the highest growth $\left(\mathrm{OD}_{600 \mathrm{~nm}}=0.907 \pm 0.019\right.$ at $\left.24 \mathrm{~h}\right)$, while Strain WcSnc45 showed the lowest $\left(\mathrm{DO}_{600 \mathrm{~nm}}=0.494 \pm 0.013\right.$ after $24 \mathrm{~h}$ ) (Figure 2A); culture $\mathrm{pH}$ remained constant in all cases. Hydrolysis of birch xylan produces XOS and xylose monomers, so it was important to confirm that the growth observed was due to XOS breakdown and not to xylose metabolism only. The analysis of XOS consumption followed by TLC analysis throughout the culture showed that all strains prefer to metabolize short-chain XOS, consuming almost all $\mathrm{X}_{1}, \mathrm{X}_{2}$, and $\mathrm{X}_{3}$; while $\mathrm{X}_{4}$ decreased more slowly over time (results not shown). Given its preferential growth (Figures 2A,B), strain WcL17 was selected to evaluate the XOS consumption kinetics by HPAEC-PAD, confirming the preferential uptake of short-chain XOS. After $24 \mathrm{~h}$ of growth, $\mathrm{X}_{3}$ and $\mathrm{X}_{4}$ were almost completely metabolized (91.9 and $99.8 \%$, respectively), while $X_{1}$ and $X_{2}$ were consumed to a great extent (70 and $92.1 \%$ ), as shown in Figures 2C,D. XOS analysis could be fully appreciated only by HPAEC-PAD. To further demonstrate the presence of the xylosidase activity in XOS WcL17 cultures, we performed reactions spiking XOS as substrate and using the 3, 6, and 12-h culture supernatants as a source of xylosidase and monitored its consumption with both TLC and HPAEC-PAD after $5 \mathrm{~h}$ of reaction. Again, the reduction of $\mathrm{X}_{2}, \mathrm{X}_{3}$, and $\mathrm{X}_{4}$ along with the accumulation of $\mathrm{X}_{1}$ (xylose) was demonstrated with both techniques (Figures 2E,F). The highest enzymatic activity was observed in $12 \mathrm{~h}$-culture supernatants, showing a direct relation between xylosidase activity and growth.

\section{Growth Kinetics and Enzymatic Activity on Sucrose}

The growth profile on sucrose as substrate was evaluated in order to address another aspect related to the role of Weissella in pozol fermentation, considering that sucrose is not only found in maize seeds but also frequently added to pozol before consumption. It is known that Weissella species are able to produce polysaccharides from sucrose (20). We found that all strains assayed had the ability to grow on sucrose as carbon source; WcSnc40, WcSnc45, and WCP-3a showed greater growth and higher enzymatic activity relative to WcL17 and WcL9 (Figure 3A). A dramatic reduction in enzyme activity was also observed in supernatants after $6 \mathrm{~h}$ relative to $3 \mathrm{~h}$ of culture (Supplementary Table 2). Given this behavior, growth curves, enzymatic activity, and metabolized substrate were quantified for those strains showing high $\mathrm{OD}_{600 \mathrm{~nm}}$. A lag phase of around $1 \mathrm{~h}$ was observed for WcSnc40 and WCP-3a cultures, and $0.5 \mathrm{~h}$ for WcSnc45. All strains ended the exponential growth and shifted to the pre-stationary phase after $3 \mathrm{~h}$ of culture, with peak enzymatic activity at $3 \mathrm{~h}$ of culture and a drop in $\mathrm{pH}$ after $3.5 \mathrm{~h}$ of culture, to remain constant thereafter (Figures 3B-D and Supplementary Table 3). Sucrose decreased during the exponential growth phase and was depleted after $6 \mathrm{~h}$ of culture, when strains reached the stationary phase. Interestingly, fructose release to the medium started after $1 \mathrm{~h}$ of culture, decreasing from $3 \mathrm{~h}$ onward, while glucose was readily used. This behavior suggests that glucose is used not only as carbon and energy source but also as a substrate for polysaccharide production, releasing fructose into the medium in both cases, which is metabolized once sucrose is depleted (Figures 3E-G). This was confirmed by the presence of active extracellular glucosyltransferase activity, which accounts for fructose release and, particularly, for the increase in medium viscosity, a finding not observed when XOS were used as carbon source. A fact worth mentioning is that GTF activity measured for WCP-3a on sucrose is $0.51 \pm 0.13 \mathrm{U} / \mathrm{mL}$ after $3 \mathrm{~h}$ of culture, whereas WcSnc40 and WcSnc45 show an enzymatic activity of $0.132 \pm 0.046$ and $0.121 \pm 0.026 \mathrm{U} / \mathrm{mL}$, respectively, for this same time (Supplementary Table 3). Interestingly, after $4 \mathrm{~h}$ of culture, the enzymatic activity for the three strains falls drastically and remains stable thereafter (Supplementary Table 3). Due to its higher activity, we selected strain WCP-3a (Figure $\mathbf{3 H}$ ) for genome sequencing.

\section{Genome Assembly and Taxonomic Assignment}

The results obtained in the XOS and sucrose consumption kinetics experiments supported the selection of two strains for genomic sequencing, looking for genes that encode enzymatic activities on carbohydrates to explore their potential role in pozol fermentation. WcL17 was selected for its ability to metabolize XOS (Figure 2B), while WCP-3a was selected for its GTF activity (Figure $3 \mathbf{H}$ ).

A total of 6,204,472 paired-end reads were obtained for WcL17 and 7,394,234 for WCP-3a. After quality- screening with TrimGalore, effective reads were reduced to $6,185,922$ and 7,340,348, respectively. Thirty contigs (N50 155,975 and L50 5) 

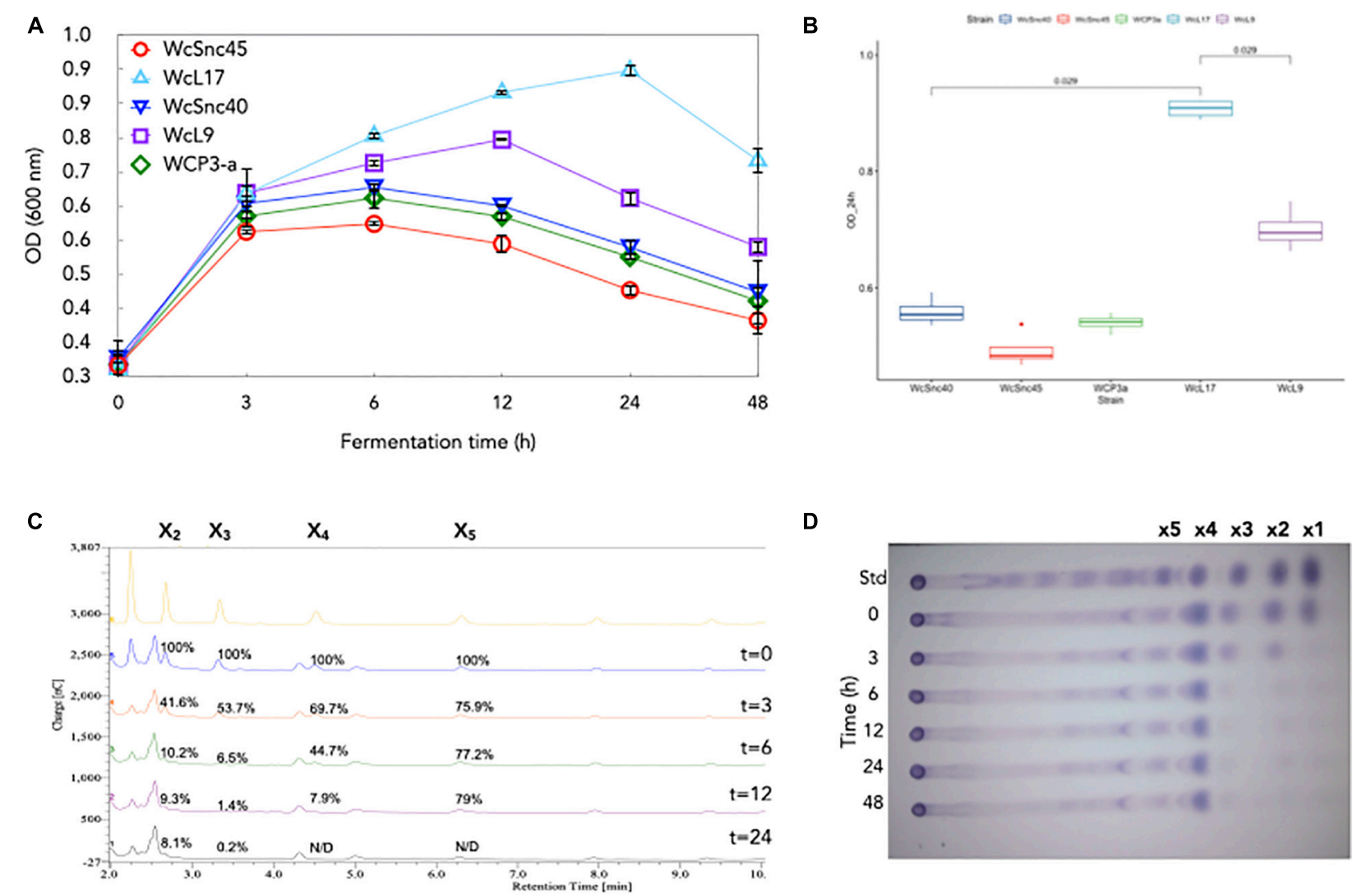

D

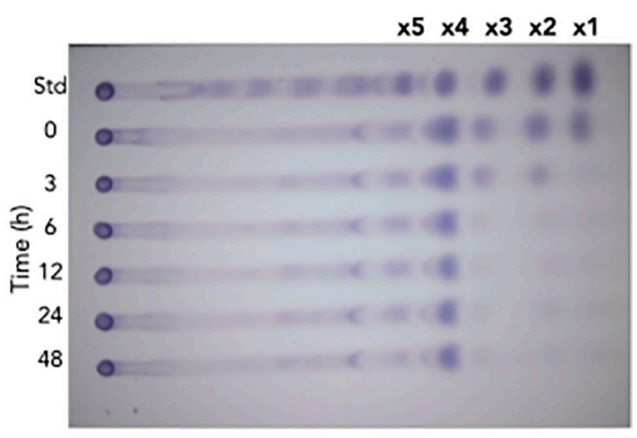

$\mathbf{E}$

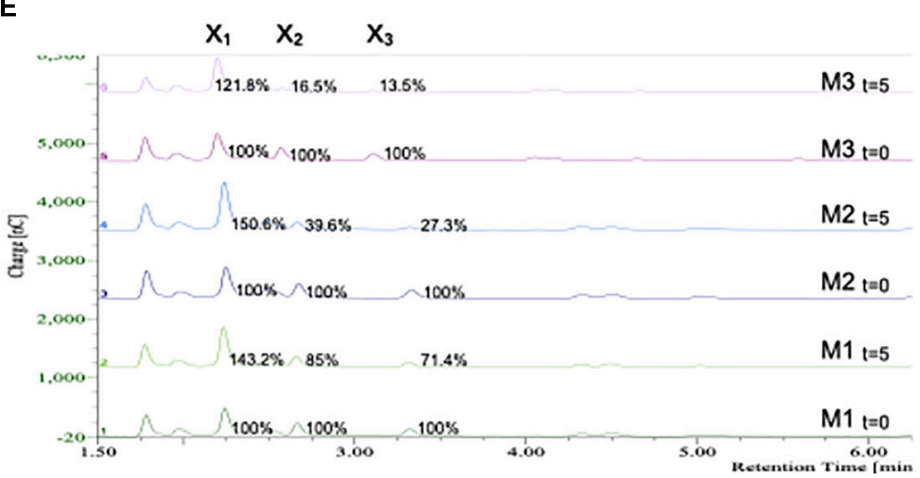

$\mathbf{F}$

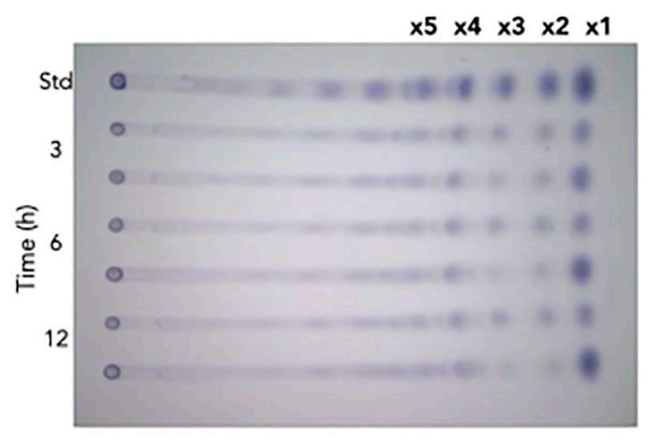

FIGURE 2 | Growth and profile of xylooligosaccharides (XOS) in cultures with five Weissella strains isolated from pozol. (A) Biomass accumulation (OD) during fermentation. (B) Biomass accumulation (OD) after $24 \mathrm{~h}$ of growth. Statistically significant differences $(p<0.5)$ for strain WcL17 growth were obtained with the ggpubr package in R v4.0.2. XOS consumption during strain WcL17 culture was evaluated by (C) HPAEC-PAD chromatograms and (D) TLC plates. XOS hydrolysis by xylosidase activity in samples from WcL17 culture at M1 $=3 \mathrm{~h}, \mathrm{M} 2=6 \mathrm{~h}$, and M3 $=12 \mathrm{~h}$ were also evaluated at baseline $(t=0)$ and after $5 \mathrm{~h}(t=5)$ of reaction by (E) HPAEC-PAD chromatograms and (F) TLC plates.

and 45 contigs (N50 119,794 and L50 5) were obtained for WcL17 and WCP-3a, respectively, with an estimated genome size of $2.31 \mathrm{Mb}(390 \mathrm{x}$ coverage) and $2.22 \mathrm{Mb}(482 \mathrm{x}$ coverage). Gene prediction and annotation indicated a total of 2,213 coding DNA sequences (CDSs) 117 tRNAs and 6 rRNAs for WcL17; and 2,163 CDSs, 110 tRNA, and 14 rRNAs for WCP-3a. The percentage of $\mathrm{G}+\mathrm{C}$ content was almost identical in both genomes, with $44.66 \%$ for WcL17 and $44.67 \%$ for WCP-3a.
The taxonomic identity of the strains sequenced was confirmed through maximum likelihood analyses of housekeeping genes (Supplementary Figure 4) and 55 ribosomal proteins (Supplementary Figure 5). The support of branches clustering the strains sequenced was $100 \%$ within the $W$. confusa clade of strains from France, China, Indonesia, and Africa (Table 1). The ANIm analysis for the whole genome also confirmed that the strains WCP-3a and WcL17 correspond to 

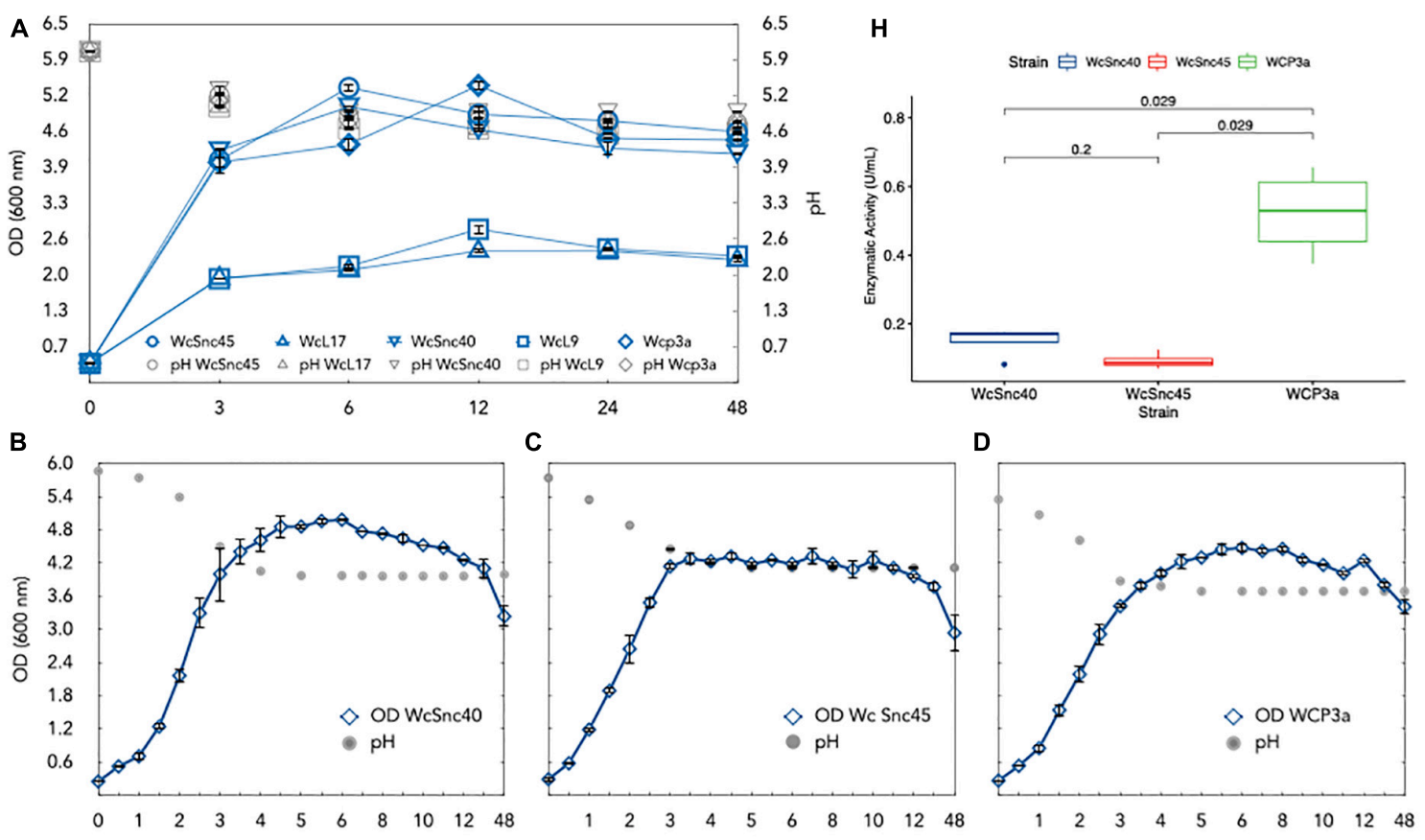

C

D
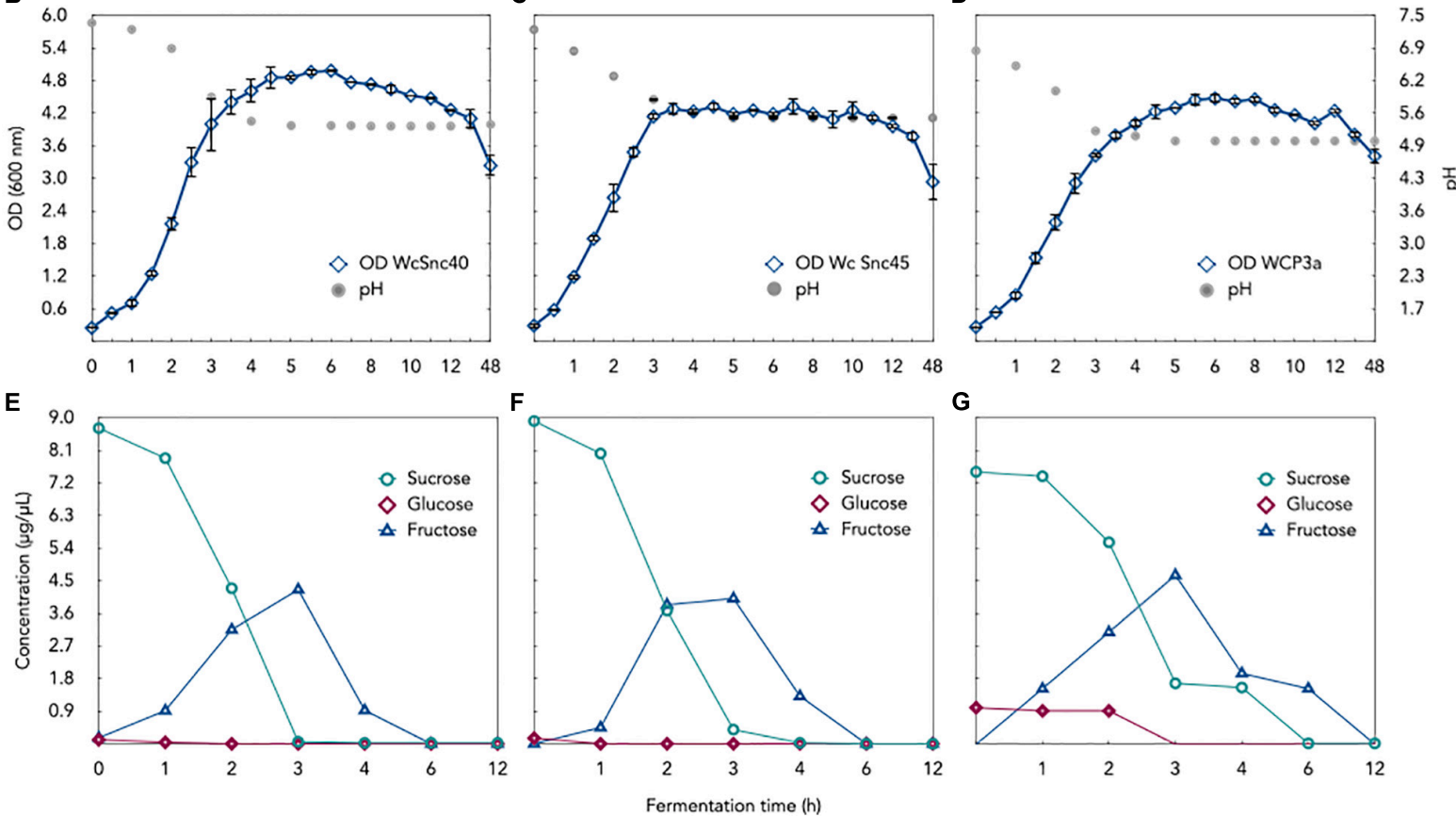

FIGURE 3 | Culture of five Weissella strains isolated from pozol in MRS-sucrose medium. (A) Biomass evolution (OD) of the five strains. The three strains with the highest growth, namely (B) WcSnc40, (C) WcSnc45, and (D) WCP3a, were studied in terms of growth (OD) and evolution of pH. Metabolized sucrose, glucose, and fructose were also monitored by HPLC analysis in the three Weissella cultures: strains (E) WcSnc40, (F) WcSnc45, and (G) WCP3a. Finally, extracellular glycosyltransferase activity $(\mathrm{U} / \mathrm{mL})$ for the three strains in 6-h cultures was compared $\mathbf{( H )}$; statistically significant differences in activity $(p<0.5)$ were obtained with the ggpubr package in $\mathrm{R}$ v4.0.2.

$W$. confusa, with values between $97.7 \%$ and $98.5 \%$ within the species. The ANIm value between WCP-3a and WcL17 was 97.9\%, whereas values between 86.9 and $87.7 \%$ were found in relation to the closest species, $W$. cibaria (Figure 4) (refer to the Github repository for the raw percentage results).

\section{Comparative Genomic of Active Carbohydrate Enzymes Through the Genus Weissella}

The search of CAZymes indicated that the genomes of WcL17 and WCP-3a encode enzymes corresponding to 43 out of the 308 families classified in the CAZy database, with a total of 87 and 79 genes from the WcL17 and WCP-3a genomes, respectively, corresponding to any of these families. These results show that $W$. confusa and $W$. cibaria contain a higher number of CAZymes analyzed relative to all species in the genus. Interestingly, this pair of species also stands out for the content of glycosyl hydrolase (GH) families acting on hemicellulose residues, together with $W$. jogaejeotgali, $W$. paramesenteroides, and W. hellenica, all isolated from fermented cereals and vegetables (Table 1). On the other hand, enzymes belonging to the GH70 family encoding GTFs were found only in $W$. confusa and $W$. cibaria, with both species already reported as producers of exopolysaccharides. Surprisingly, this analysis showed that WcL17 and WCP-3a contain genes from various subfamilies of the GH13 family, encoding a diverse group of amylases; the subfamilies present in the genomes of our strains act on starch residues. In this sense, the CAZy analysis shows a wide potential of WCL17 and WCP-3a to degrade hemicellulose and starch residues, since both strains possess genes responsible for accessory enzymatic activities, 


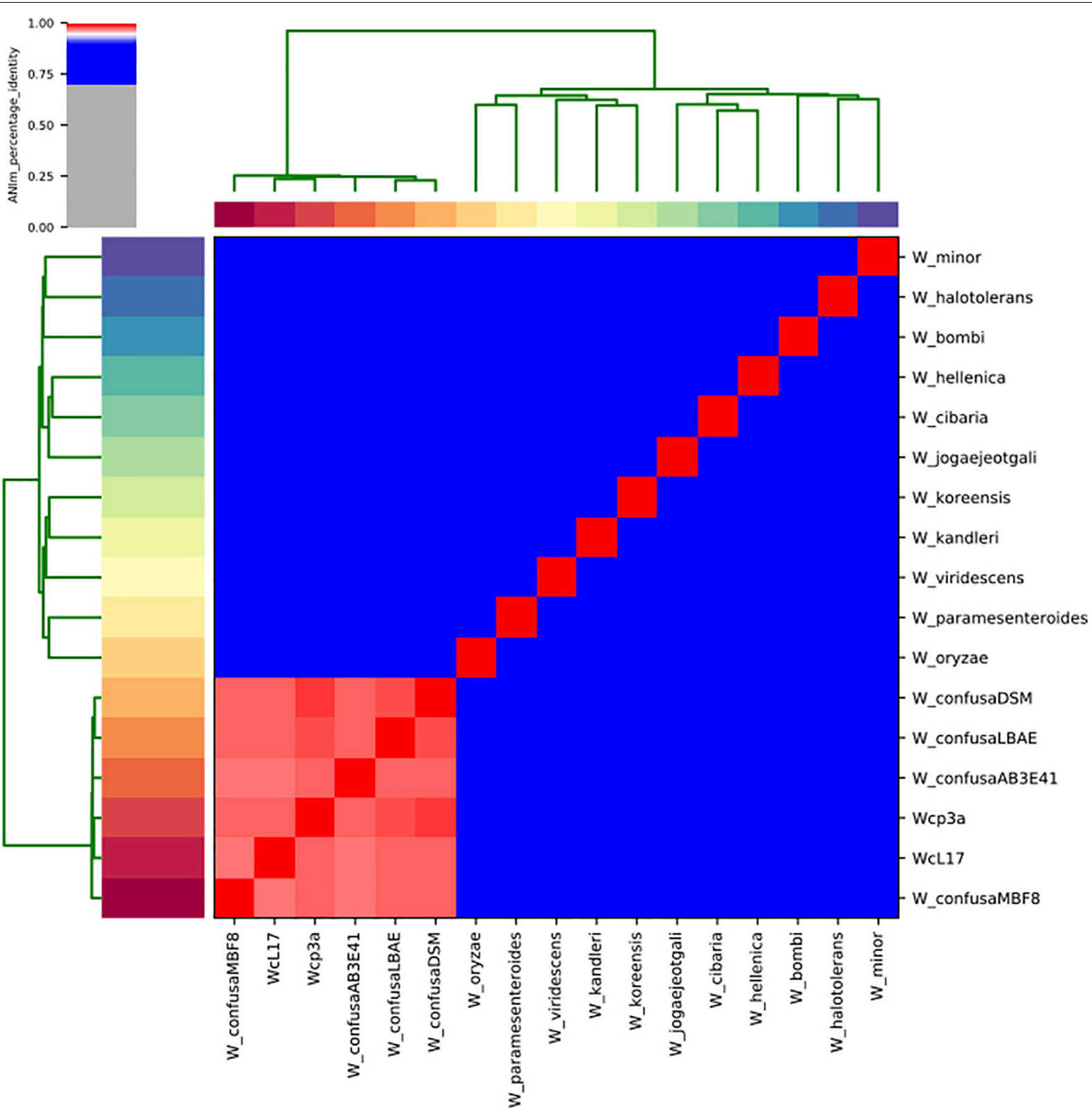

FIGURE 4 | Heatmap of Average Nucleotide Identity (ANI) values of representative Weissella genera reported in the literature (Table 1), including genomes for strains WcL17 and WCP3a. Strains with ANI values $>90 \%$ are shown within red squares.

in addition to their ability to synthesize polysaccharides from sucrose (Figure 5).

\section{DISCUSSION}

Our results on relative abundance throughout the pozol fermentation process support the hypothesis that the dominant species over the process belong to the genus Streptococcus (Ampe et al., 1999b; ben Omar and Ampe, 2000; Wacher et al., 2000; Escalante et al., 2001; Bolaños et al., 2006; Cárdenas et al., 2014). Also, we confirmed that the genera Enterococcus, Leuconostoc,
Lactococcus, and Lactobacillus are equally abundant in this process. Particularly, although not among the most numerous bacteria initially present, the abundance of Weissella increases steadily over the fermentation process until it attains a relative abundance similar to that reported in products such as togwa, sourdough, chicha, or fermented maize bran (Mugula et al., 2003; Bounaix et al., 2010; Elizaquível et al., 2015; Decimo et al., 2017). This may be explained by the importance of Weissella playing a supplementary metabolic role in the process, complementing the xylanolytic and amylolytic capacity of $S$. infantarius (CooperBribiesca et al., 2018) due to the ability of $W$. confusa to break down residual oligosaccharides produced from polymers 


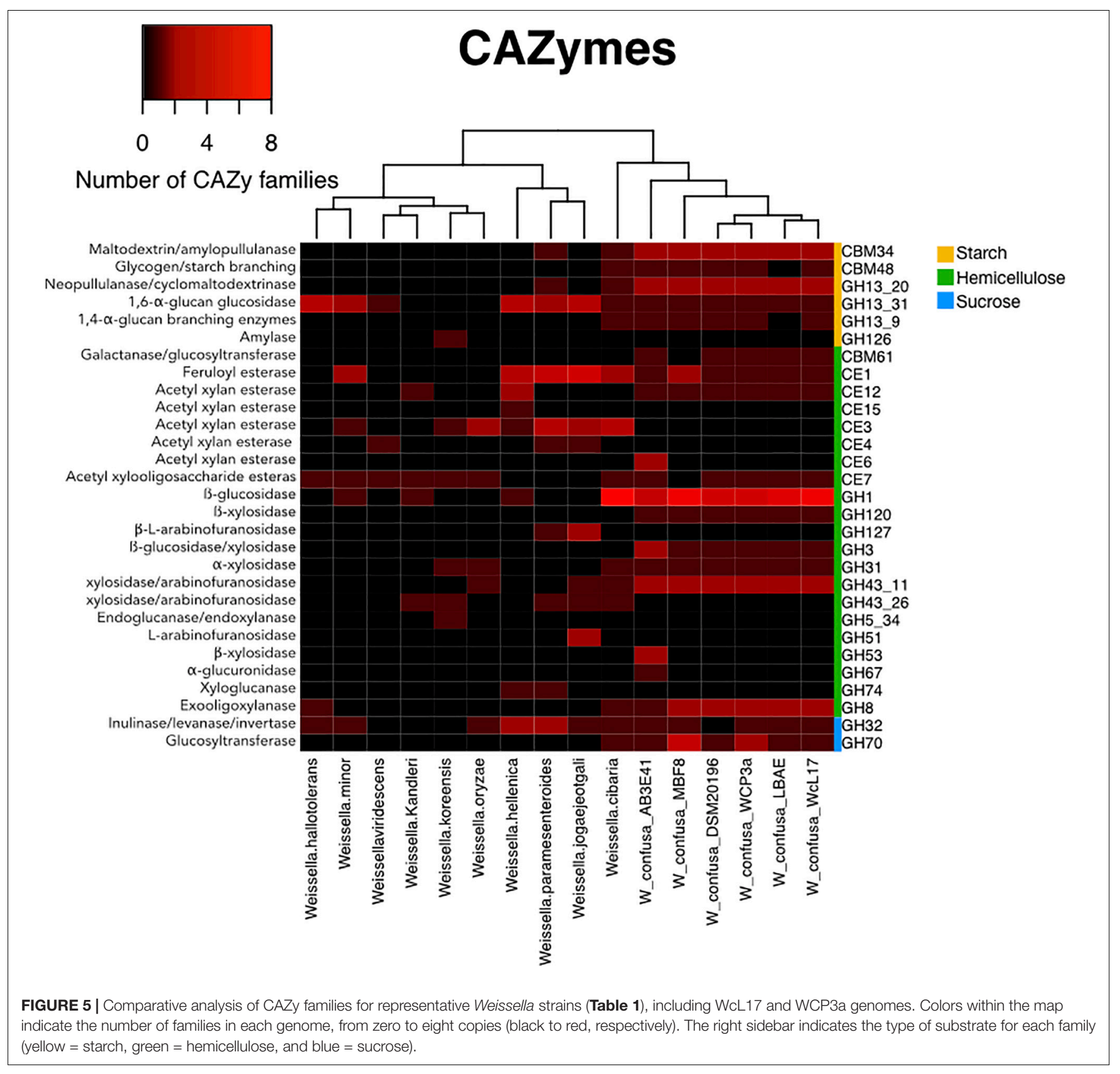

like xylan and starch during nixtamalization. This could be happening in spite of the low abundance of Weissella, as recently reported for the core fouling-causing microbiota in a membrane bioreactor, where low abundance taxa perform important functions (Zhang et al., 2018). This is also the case of nitrogen fixation in pozol carried out by Klebsiella, Enterobacter, and Kosakonia genera (Rizo et al., 2020), all of which perform important functions in the process in spite of their low abundance $(<0.05 \%$, in this work).

The limited growth and nil enzymatic activity on birch xylan became meaningful in the genomic analyses since no gene encoding endo- $\beta$-xylanase was found in the Weissella strains. Similar studies reported neither xylanolytic activity in strains of
$W$. cibaria and $W$. confusa isolated from Indian fermented foods (idli and dahi) (Patel et al., 2013) nor growth in wheat bran xylan (Immerzeel et al., 2014). However, López-Hernández et al. (2018) reported growth of $W$. confusa L9 strain on oat xylan as the only carbon source. Our results differ from those of López Hernandez et al. probably because of the structural differences of the birch xylan used in our study, as this polysaccharide may be less susceptible to $W$. confuse enzymes, which according to their genome, could only produce an exo-oligo-xylanase (Figure 5).

Strain WcL17 showed greater growth on XOS than the rest of the strains studied, but CAZy analyses showed that WcL17 and WCP-3a have the same number and type of putative enzymes from $\mathrm{GH}$ families encoding XOS activities, corresponding to 
GH43, GH3, and GH120 for $\beta$-xylosidase and GH31 for $\alpha$-xylosidase. The $\beta$-xylosidases of $\mathrm{WcL} 17$ are probably more efficient than those of WCP-3a; however, the characterization and subsequent comparison of these enzymes is required to address this question. On the other hand, the fact that WcL17 possesses this genetic arsenal in addition to its preference for short-chain XOS, as demonstrated by TLC and HPAEC-PAD analyses, shows that this strain has the ability to thrive in environments where this substrate is available. Such environments include pozol, requiring either a previous enzymatic hydrolysis of xylan by other microorganisms such as S. infantarius (Cooper-Bribiesca et al., 2018), or simply consuming XOS available after the alkaline treatment of maize in the nixtamalization process. The metabolism of short-chain XOS by $W$. confusa has been reported in strains isolated from fermented Indian cereals and vegetables, particularly by a $\beta$-xylosidase from the GH43 family (Patel et al., 2013; Immerzeel et al., 2014; Falck et al., 2016).

Cell growth and the presence of GTF activity demonstrate that the strains studied are able to readily degrade and process sucrose; WCP-3a displayed a higher enzymatic activity as well as a larger number of GH70 CAZymes encluding GTFs than the rest of the strains studied. This type of activity has been extensively studied in other Weissella confusa strains isolated from fermented foods such as sourdough wheat bran (Katina et al., 2009: Kajala et al., 2016); it is known that several strains of the $W$. confusa and $W$. cibaria are capable of producing dextran from sucrose, a glucose polymer also produced in fermented foods by Lactobacillus enzymes (Schmid et al., 2015). Among various applications, this polymer is used in the food industry because of its rheological and organoleptic properties. Strains of Weissella confusa have been reported to produce dextran and isomalto-oligosaccharides from the fermentation of sourdough, rye bran, and wheat bran (Katina et al., 2009: Kajala et al., 2016). We suggest that similar to other fermented foods, dextran is probably synthesized during pozol fermentation, conferring organoleptic and nutritional properties. Nevertheless, this aspect should be explored in future studies. Enzymes in the GH70 family are currently being characterized by our research group.

The phylogenetic (Supplementary Figures 4, 5) and ANIm (Figure 4) analyses confirmed the taxonomic identity of the genomes assembled in this investigation. The use of housekeeping markers and ribosomal proteins are an alternative to the challenges involved in taxonomic assignment based on $16 \mathrm{~S}$ rRNA alone (Janda and Abbott, 2007) when dealing with closely related species such as $W$. confusa and $W$. cibaria, which share $87.7 \%$ of the average nucleotide identity (Björkroth et al., 2002).

The genomic analyses showed that the strains sequenced in this work have GHs acting on the substrates evaluated in the growth kinetic studies on XOS (GH43, GH3, and GH150) and sucrose (GH32 and GH70), except for xylan, in addition to genes corresponding to carboxylesterases (CE) acting on xylan decorations (CE1, CE12, and CE7). Surprisingly, the CAZy results showed alternative capacities of the WcL17 and WCP-3a strains that had not been considered previously, such as GH1 and GH8 genes encoding $\beta$-glucosidase and endo-1,4- $\beta$-glucanase, enzymes that are capable of degrading cellulose. Also interesting was the finding of the enzyme families GH13_20, GH13_31, GH13_9, which include enzymes acting on starch residues and containing the starch-binding domains CBM34 and CBM48. These findings also explain the nil detection of amylases by López-Hernández et al. (2018), as well as a potential role of starch residues in the fermentation process of the nixtamalized corn dough used in pozol elaboration.

Our work highlights the important supplementary metabolic role of Weissella confusa in the pozol fermentation process due to its activity on oligosaccharides derived from xylan-and eventually cellulose or starch-as well as its role in the synthesis of polysaccharides via GTFs.

\section{DATA AVAILABILITY STATEMENT}

Genome assemblies and raw data are available at GenBank under the BioProject PRJNA642311. Amplicon sequencing data are available under the BioProject number PRJNA648868. The code used for the all bioinformatic analysis and complete results of each are found in: https://github.com/DianaOaxaca/Weissella_ analysis.git.

\section{AUTHOR CONTRIBUTIONS}

AL, LS, and CW designed the experiments, gave general supervision, and wrote the manuscript. $\mathrm{DH}$ did all the experimental work and comparative genomics. RL did sequencing $16 \mathrm{~S}$ analysis. DH and RL wrote the initial version of the manuscript. LL supported the Weissella taxonomy and phylogeny study. All authors contributed to the article and approved the submitted version.

\section{FUNDING}

$\mathrm{DH}$ and RL were master's in science students in the Ciencias Bioquimicas Program at UNAM, supported by a fellowship from Consejo Nacional de Ciencia y Tecnología (CONACYT), México. This work was supported by UNAM/DGAPA/PAPIIT/IN22391 and by CONACYT project A1-S-21209

\section{ACKNOWLEDGMENTS}

We would like to thank Romina Rodríguez-Sanoja, Jocelin Rizo from IIB-UNAM, Judith Espinoza, and Dora Centurión from the Universidad Juárez Autónoma de Tabasco for their valuable information on pozol traditions and sampling in Villahermosa, Tabasco. We would also like to thank Heladia Salgado-Osorio for the Center of Genomic Science cluster access. We would also like to thank Maria Elena Rodriguez-Alegría and Fernando Gonzalez-Muñoz for technical support. María Elena SánchezSalazar supported us in translation and edition of the manuscript.

\section{SUPPLEMENTARY MATERIAL}

The Supplementary Material for this article can be found online at: https://www.frontiersin.org/articles/10.3389/fmicb.2021. 629449/full\#supplementary-material 


\section{REFERENCES}

Abegaz, K. (2007). Isolation, characterization and identification of lactic acid bacteria involved in traditional fermentation of borde, an Ethiopian cereal beverage. Afr. J. Biotechnol. 6, 1469-1478.

Akpinar, O., Erdogan, K., and Bostanci, S. (2009). Production of xylooligosaccharides by controlled acid hydrolysis of lignocellulosic materials. Carbohydr. Res. 344, 660-666. doi: 10.1016/j.carres.2009.01.015

Ampe, F., ben Omar, N., Moizan, C., Wacher, C., and Guyot, J. P. (1999a). Polyphasic study of the spatial distribution of microorganisms in Mexican pozol, a fermented maize dough, demonstrates the need for cultivationindependent methods to investigate traditional fermentations. Appl. Environ. Microbiol. 65, 5464-5473. doi: 10.1128/AEM.65.12.5464-5473.1999

Ampe, F., and Miambi, E. (2000). Cluster analysis, richness and biodiversity indexes derived from denaturing gradient gel electrophoresis fingerprints of bacterial communities demonstrate that traditional maize fermentations are driven by the transformation process. Int. J. Food Microbiol. 60, 91-97. doi: 10.1016/S0168-1605(00)00358-5

Ampe, F., Omar, N. B., and Guyot, J. P. (1999b). Culture-independent quantification of physiologically active microbial groups in fermented foods using rRNA-targeted oligonucleotide probes: application to pozol, a Mexican lactic acid fermented maize dough. J. Appl. Microbiol. 87, 131-140. doi: 10. 1046/j.1365-2672.1999.00803.x

Ayeni, F. A., Sánchez, B., Adeniyi, B. A., Clara, G., Margolles, A., and RuasMadiedo, P. (2011). Evaluation of the functional potential of Weissella and Lactobacillus isolates obtained from Nigerian traditional fermented foods and cow's intestine. Int. J. Food Microbiol. 147, 97-104. doi: 10.1016/j.ijfoodmicro. 2011.03.014

Bankevich, A., Nurk, S., Antipov, D., Gurevich, A. A., Dvorkin, M., Kulikov, A. S., et al. (2012). SPAdes: a new genome assembly algorithm and its applications to single-cell sequencing. J. Comp. Biol. 19, 455-477. doi: 10.1089/cmb.2012. 0021

ben Omar, N., and Ampe, F. (2000). Microbial community dynamics during production of the Mexican fermented maize dough pozol. Appl. Environ. Microbiol. 66, 3664-3673. doi: 10.1128/AEM.66.9.3664-3673.2000

Bengtsson-Palme, J., Hartmann, M., Eriksson, K. M., Pal, C., Thorell, K., Larsson, D. G. J., et al. (2015). METAXA2: improved identification and taxonomic classification of small and large subunit rRNA in m10.1111/17550998.12399etagenomic data. Mol. Ecol. Resour. 15, 1403-1414. doi:

Björkroth, K. J., Schillinger, U., Geisen, R., Weiss, N., Hoste, B., Holzapfel, W. H., et al. (2002). Taxonomic study of Weissella confusa and description of Weissella cibaria sp. nov., detected in food and clinical samples. Int. J. Syst. Evol. Microbiol. 52, 141-148. doi: 10.1099/00207713-52-1-141

Boetzer, M., Henkel, C. V., Jansen, H. J., Butler, D., and Pirovano, W. (2011). Scaffolding pre-assembled contigs using SSPACE. Bioinformatics 27, 578-579. doi: 10.1093/bioinformatics/btq683

Boetzer, M., and Pirovano, W. (2012). Toward almost closed genomes with GapFiller. Genome Biol. 13:R56. doi: 10.1186/gb-2012-13-6-r56

Bolaños, S., López, G., Pérez, A., Guyot, J. P., and Wacher, C. (2006). "Study on the variability in the microbial composition of pozol from different producers, using 16S rRNA and rpoB PCR-DGGE," in Proceedings of the 11th International Symposium on Microbial Ecology (ISME-11), (Vienna: Cartel).

Bounaix, M. S., Gabriel, V., Robert, H., Morel, S., Remaud-Siméon, M., Gabriel, B., et al. (2010). Characterization of glucan-producing Leuconostoc strains isolated from sourdough. Int. J. Food Microbiol. 144, 1-9. doi: 10.1016/j.ijfoodmicro. 2010.05.026

Cárdenas, C., Barkla, B. J., Wacher, C., Delgado-Olivares, L., and Rodríguez-Sanoja, R. (2014). Protein extraction method for the proteomic study of a Mexican traditional fermented starchy food. J. Proteomics 111, 139-147. doi: 10.1016/ j.jprot.2014.06.028

Cooper-Bribiesca, B., Navarro-Ocaña, A., Díaz-Ruiz, G., Aguilar-Osorio, G., Rodríguez-Sanoja, R., and Wacher, C. (2018). Lactic acid fermentation of arabinoxylan from nejayote by Streptococcus infantarius ssp. infantarius 25124 isolated from pozol. Front. Microbiol. 9:3061. doi: 10.3389/fmicb.2018.03061

Darriba, D., Taboada, G. L., Doallo, R., and Posada, D. (2011). ProtTest 3: fast selection of best-fit models of protein evolution. Bioinformatics 27, 1164-1165. doi: 10.1093/bioinformatics/btr088

Decimo, M., Quattrini, M., Ricci, G., Fortina, M. G., Brasca, M., Silvetti, T., et al. (2017). Evaluation of microbial consortia and chemical changes in spontaneous maize bran fermentation. AMB Express 7:205. doi: 10.1186/s13568-017-0506-y
Díaz-Ruiz, G., Guyot, J. P., Ruiz-Teran, F., Morlon-Guyot, J., and Wacher, C. (2003). Microbial and physiological characterization of weakly amylolytic but fast-growing lactic acid bacteria: a functional role in supporting microbial diversity in pozol, a Mexican fermented maize beverage. Appl. Environ. Microbiol. 69, 4367-4374. doi: 10.1128/AEM.69.8.4367-4374.2003

Eddy, S. R. (2011). Accelerated profile HMM searches. PLoS Comput. Biol. 7:e1002195. doi: 10.1371/journal.pcbi.1002195

Edgar, R. C. (2004). MUSCLE: multiple sequence alignment with high accuracy and high throughput. Nucleic Acids Res. 32, 1792-1797. doi: 10.1093/nar/gkh340

Elizaquível, P., Pérez-Cataluña, A., Yépez, A., Aristimuño, C., Jiménez, E., Cocconcelli, P. S., et al. (2015). Pyrosequencing vs. culture-dependent approaches to analyze lactic acid bacteria associated to chicha, a traditional maize-based fermented beverage from Northwestern Argentina. Int. J. Food Microbiol. 198, 9-18. doi: 10.1016/j.ijfoodmicro.2014.12.027

Escalante, A., Wacher, C., and Farres, A. (2001). Lactic acid bacterial diversity in the traditional Mexican fermented dough pozol as determined by $16 \mathrm{~S}$ rDNA sequence analysis. Int. J. Food Microbiol. 64, 21-31. doi: 10.1016/S01681605(00)00428-1

Escobar-Zepeda, A., Godoy-Lozano, E. E., Raggi, L., Segovia, L., Merino, E., Gutiérrez-Rios, R. M., et al. (2018). Analysis of sequencing strategies and tools for taxonomic annotation: defining standards for progressive metagenomics. Sci. Rep. 8:12034. doi: 10.1038/s41598-018-30515-5

Falck, P., Linares-Pastén, J. A., Adlercreutz, P., and Karlsson, E. N. (2016). Characterization of a family $43 \beta$-xylosidase from the xylooligosaccharide utilizing putative probiotic Weissella sp. strain 92. Glycobiology 26, 193-202. doi: 10.1093/glycob/cwv092

Fusco, V., Quero, G. M., Cho, G. S., Kabisch, J., Meske, D., Neve, H., et al. (2015). The genus Weissella: taxonomy, ecology and biotechnological potential. Front. Microbiol. 6:155. doi: 10.3389/fmicb.2015.00155

Immerzeel, P., Falck, P., Galbe, M., Adlercreutz, P., Karlsson, E. N., and Stålbrand, H. (2014). Extraction of water-soluble xylan from wheat bran and utilization of enzymatically produced xylooligosaccharides by Lactobacillus, Bifidobacterium and Weissella spp. LWT Food Sci. Technol. 56, 321-327. doi: 10.1016/j.lwt.2013. 12.013

Janda, J. M., and Abbott, S. L. (2007). 16S rRNA gene sequencing for bacterial identification in the diagnostic laboratory: pluses, perils, and pitfalls. J. Clin. Microbiol. 45, 2761-2764. doi: 10.1128/JCM.01228-07

Kajala, I., Mäkelä, J., Coda, R., Shukla, S., Shi, Q., Maina, N. H., et al. (2016). Rye bran as fermentation matrix boosts in situ dextran production by Weissella confusa compared to wheat bran. Appl. Microbiol. Biotechnol. 100, 3499-3510. doi: 10.1007/s00253-015-7189-6

Katina, K., Maina, N. H., Juvonen, R., Flander, L., Johansson, L., Virkki, L., et al. (2009). In situ production and analysis of Weissella confusa dextran in wheat sourdough. Food Microbiol. 26, 734-743. doi: 10.1016/j.fm.2009. 07.008

Kavitake, D., Devi, P. B., Singh, S. P., and Shetty, P. H. (2016). Characterization of a novel galactan produced by Weissella confusa KR780676 from an acidic fermented food. Int. J. Biol. Macromol. 86, 681-689. doi: 10.1016/j.ijbiomac. 2016.01.099

Klindworth, A., Pruesse, E., Schweer, T., Peplies, J., Quast, C., Horn, M., et al. (2013). Evaluation of general 16S ribosomal RNA gene PCR primers for classical and next-generation sequencing-based diversity studies. Nucleic Acids Res. 41:e1. doi: 10.1093/nar/gks808

Krueger, F. (2015). Trim Galore. A Wrapper Tool Around Cutadapt and FastQC to Consistently Apply Quality and Adapter Trimming to FastQ Files. Cambridge: Babraham Bioinformatics. Vol. 516, 517.

Lee, K. W., Park, J. Y., Chun, J. Y., Han, N. S., and Kim, J. H. (2010). Importance of Weissella species during kimchi fermentation and future works. Microbiol. Biotechnol. Lett. 38, 341-348.

Liu, C. J., Gong, F. M., Li, X. R., Li, H. Y., Zhang, Z. H., Feng, Y., et al. (2012). Natural populations of lactic acid bacteria in douchi from Yunnan Province, China. J. Zhejiang Univ. Sci. B 13, 298-306. doi: 10.1631/jzus.B110 0221

López-Hernández, M., Rodríguez-Alegría, M. E., López-Munguía, A., and Wacher, C. (2018). Evaluation of xylan as carbon source for Weissella spp., a predominant strain in pozol fermentation. LWT 89, 192-197. doi: 10.1016/j. lwt.2017.10.030

Lorusso, A., Coda, R., Montemurro, M., and Rizzello, C. G. (2018). Use of selected lactic acid bacteria and quinoa flour for manufacturing novel yogurt-like beverages. Foods 7:51. doi: 10.3390/foods7040051 
Magoč, T., and Salzberg, S. L. (2011). FLASH: fast length adjustment of short reads to improve genome assemblies. Bioinformatics 27, 2957-2963. doi: 10.1093/ bioinformatics/btr507

Malang, S. K., Maina, N. H., Schwab, C., Tenkanen, M., and Lacroix, C. (2015). Characterization of exopolysaccharide and ropy capsular polysaccharide formation by Weissella. Food Microbiol. 46, 418-427. doi: 10.1016/j.fm.2014. 08.022

McMurdie, P. J., and Holmes, S. (2013). phyloseq: an R package for reproducible interactive analysis and graphics of microbiome census data. PLoS One 8:e61217. doi: 10.1371/journal.pone.0061217

Miller, G. L. (1959). Use of dinitrosalicylic acid reagent for determination of reducing sugar. Anal. Chem. 31, 426-428. doi: 10.1021/ac60147a030

Mugula, J. K., Nnko, S. A. M., Narvhus, J. A., and Sørhaug, T. (2003). Microbiological and fermentation characteristics of togwa, a Tanzanian fermented food. Int. J. Food Microbiol. 80, 187-199. doi: 10.1016/S01681605(02)00141-1

Nuraida, L., Wacher, M. C., and Owens, J. D. (1995). Microbiology of pozol, a Mexican fermented maize dough. World J. Microbiol. Biotechnol. 11, 567-571. doi: 10.1007/BF00286375

Oguntoyinbo, F. A., Tourlomousis, P., Gasson, M. J., and Narbad, A. (2011). Analysis of bacterial communities of traditional fermented West African cereal foods using culture independent methods. Int. J. Food Microbiol. 145, 205-210. doi: 10.1016/j.ijfoodmicro.2010.12.025

Oksanen, J., Blanchet, F. G., Kindt, R., Legendre, P., Minchin, P., O’Hara, R. B., et al. (2012). R Package Version 2.0-2. Vegan: Community Ecology Package.

Olivares-Illana, V., Wacher-Rodarte, C., Le Borgne, S., and López-Munguía, A. (2002). Characterization of a cell-associated inulosucrase from a novel source: a Leuconostoc citreum strain isolated from Pozol, a fermented corn beverage of Mayan origin. J. Ind. Microbiol. Biotechnol. 28, 112-117. doi: 10.1038/sj/jim/ 7000224

Osimani, A., Garofalo, C., Aquilanti, L., Milanović, V., and Clementi, F. (2015). Unpasteurised commercial boza as a source of microbial diversity. Int. J. Food Microbiol. 194, 62-70. doi: 10.1016/j.ijfoodmicro.2014. 11.011

Owusu-Kwarteng, J., Akabanda, F., Nielsen, D. S., Tano-Debrah, K., Glover, R. L., and Jespersen, L. (2012). Identification of lactic acid bacteria isolated during traditional fura processing in Ghana. Food Microbiol. 32, 72-78. doi: 10.1016/j. fm.2012.04.010

Park, J. H., Ahn, H. J., Kim, S. G., and Chung, C. H. (2013). Dextran-like exopolysaccharide-producing Leuconostoc and Weissella from kimchi and its ingredients. Food Sci. Biotechnol. 22, 1047-1053. doi: 10.1007/s10068-0130182-x

Patel, A., Falck, P., Shah, N., Immerzeel, P., Adlercreutz, P., Stålbrand, H., et al. (2013). Evidence for xylooligosaccharide utilization in Weissella strains isolated from Indian fermented foods and vegetables. FEMS Microbiol. Lett. 346, 20-28. doi: 10.1111/1574-6968.12191

Paulson, J. N., Olson, N. D., Braccia, D. J., Wagner, J., Talukder, H., Pop, M., et al. (2013). metagenomeSeq: Statistical Analysis for Sparse High-Throughput Sequncing. Bioconductor Package. College Park, MD: Center for Bioinformatics and Computational Biology.

Phister, T. G., O'Sullivan, D. J., and McKay, L. L. (2004). Identification of bacilysin, chlorotetaine, and iturin a produced by Bacillus sp. strain CS93 isolated from pozol, a Mexican fermented maize dough. Appl. Environ. Microbiol. 70, 631634. doi: 10.1128/AEM.70.1.631-634.2004

Porras-Domínguez, J. R., Ávila-Fernández, Á, Miranda-Molina, A., RodríguezAlegría, M. E., and Munguía, A. L. (2015). Bacillus subtilis 168 levansucrase (SacB) activity affects average levan molecular weight. Carbohydr. Polym. 132, 338-344. doi: 10.1016/j.carbpol.2015.06.056

Pritchard, L., Glover, R. H., Humphris, S., Elphinstone, J. G., and Toth, I. K. (2016). Genomics and taxonomy in diagnostics for food security: soft-rotting enterobacterial plant pathogens. Anal. Methods 8, 12-24. doi: 10.1039/ C5AY02550H

Ray, P., Sanchez, C., O'Sullivan, D. J., and McKay, L. L. (2000). Classification of a bacterial isolate, from pozol, exhibiting antimicrobial activity against several gram-positive and gram-negative bacteria, yeasts, and molds. J. Food Prot. 63, 1123-1132. doi: 10.4315/0362-028X-63.8.1123

Rizo, J., Rogel, M. A., Guillén, D., Wacher, C., Martinez-Romero, E., Encarnación, S., et al. (2020). Nitrogen fixation in pozol, a traditional fermented beverage. Appl. Environ. Microbiol. doi: 10.1128/AEM.00588-20
Rizzello, C. G., Coda, R., Wang, Y., Verni, M., Kajala, I., Katina, K., et al. (2019). Characterization of indigenous Pediococcus pentosaceus, Leuconostoc kimchii, Weissella cibaria and Weissella confusa for faba bean bioprocessing. Int. J. Food Microbiol. 302, 24-34. doi: 10.1016/j.ijfoodmicro.2018.08.014

Rognes, T., Flouri, T., Nichols, B., Quince, C., and Mahé, F. (2016). VSEARCH: a versatile open source tool for metagenomics. PeerJ 4:e2584. doi: 10.7717/peerj. 2584

Sangwan, S., Kumar, S., and Goyal, S. (2014). "Maize utilisation in food bioprocessing: an overview," in Maize: Nutrition Dynamics and Novel Uses, eds D. Chaudhary, S. Kumar, and S. Langyan (New Delhi: Springer), doi: 10.1007/ 978-81-322-1623-0_10

Schmid, J., Sieber, V., and Rehm, B. (2015). Bacterial exopolysaccharides: biosynthesis pathways and engineering strategies. Front. Microbiol. 6:496. doi: $10.3389 /$ fmicb.2015.00496

Seemann, T. (2014). Prokka: rapid prokaryotic genome annotation. Bioinformatics 30, 2068-2069. doi: 10.1093/bioinformatics/btu153

Sharma, S., Kandasamy, S., Kavitake, D., and Shetty, P. H. (2018). Probiotic characterization and antioxidant properties of Weissella confusa KR780676, isolated from an Indian fermented food. LWT 97, 53-60. doi: 10.1016/j.lwt. 2018.06.033

Shukla, S., Verma, A. K., Kajala, I., Nyyssolä, A., Baruah, R., Katina, K., et al. (2016). Structure modeling and functional analysis of recombinant dextransucrase from Weissella confusa Cab3 expressed in Lactococcus lactis. Prep. Biochem. Biotechnol. 46, 822-832. doi: 10.1080/10826068.2016.1141299

Stamatakis, A. (2014). RAxML version 8: a tool for phylogenetic analysis and post-analysis of large phylogenies. Bioinformatics 30, 1312-1313. doi: 10.1093/ bioinformatics/btu033

Su, X., Pan, W., Song, B., Xu, J., and Ning, K. (2014). Parallel-META 2.0: enhanced metagenomic data analysis with functional annotation, high performance computing and advanced visualization. PLoS One 9:e89323. doi: 10.1371/ journal.pone. 0089323

Tieking, M., Korakli, M., Ehrmann, M. A., Gänzle, M. G., and Vogel, R. F. (2003). In situ production of exopolysaccharides during sourdough fermentation by cereal and intestinal isolates of lactic acid bacteria. Appl. Environ. Microbiol. 69, 945-952. doi: 10.1128/AEM.69.2.945-952.2003

Vassallo Rodríguez, M. (2016). Evanescence in translations from Chilam Balam of Chumayel: maize and beans from the South, lima beans from the East, and ritual pozol. Estudios de Cultura Maya 47, 119-150. doi: 10.19130/iifl.ecm.2016.47. 745

Wacher, C., Cañas, A., Bárzana, E., Lappe, P., Ulloa, M., and Owens, J. D. (2000). Microbiology of Indian and Mestizo pozol fermentations. Food Microbiol. 17, 251-256. doi: 10.1006/fmic.1999.0310

Wacher, C., Canas, A., Cook, P. E., Barzana, E., and Owens, J. D. (1993). Sources of microorganisms in pozol, a traditional Mexican fermented maize dough. World J. Microbiol. Biotechnol. 9, 269-274. doi: 10.1007/BF00327853

Wences, A. H., and Schatz, M. C. (2015). Metassembler: merging and optimizing de novo genome assemblies. Genome Biol. 16:207. doi: 10.1186/s13059-0150764-4

Yin, Y., Mao, X., Yang, J., Chen, X., Mao, F., and Xu, Y. (2012). dbCAN: a web resource for automated carbohydrate-active enzyme annotation. Nucleic Acids Res. 40, W445-W451. doi: 10.1093/nar/gks479

Zerbino, D. R., and Birney, E. (2008). Velvet: algorithms for de novo short read assembly using de Bruijn graphs. Genome Res. 18, 821-829. doi: 10.1101/gr. 074492.107

Zhang, S., Zhou, Z., Li, Y., and Meng, F. (2018). Deciphering the core foulingcausing microbiota in a membrane bioreactor: low abundance but important roles. Chemosphere 195, 108-118. doi: 10.1016/j.chemosphere.2017.12.067

Conflict of Interest: The authors declare that the research was conducted in the absence of any commercial or financial relationships that could be construed as a potential conflict of interest.

Copyright (C) 2021 Hernández-Oaxaca, López-Sánchez, Lozano, Wacher-Rodarte, Segovia and López Munguía. This is an open-access article distributed under the terms of the Creative Commons Attribution License (CC BY). The use, distribution or reproduction in other forums is permitted, provided the original author(s) and the copyright owner(s) are credited and that the original publication in this journal is cited, in accordance with accepted academic practice. No use, distribution or reproduction is permitted which does not comply with these terms. 